\title{
Segmental clavicle fracture with acromioclavicular joint disruption: Report of a rare case

\author{
Rao $\mathrm{AS}^{1}$, Raju LVSN ${ }^{1}$, and Naveen Kumar Banda ${ }^{1, *}$
}

${ }^{1}$ Department of Orthopaedics, Krishna Institute of Medical Sciences, Minister Road, Secunderabad-500003, Telangana, India

\begin{abstract}
Clavicle fractures are common, which accounts for $2.6 \%$ of all adult fractures, but the segmental clavicle fracture is an uncommon pattern, with one study showing $0.8 \%$ of clavicle fractures to be segmental. We present a rare case of segmental clavicle fracture (middle $1 / 3^{\text {rd }}$ and lateral end) with acromioclavicular joint (AC-joint) disruption. A lateral clavicular plate was applied fixing both fractures and K-wire for AC-joint disruption. The K-wire was removed after 6 weeks. The patient was followed up at 6 months and one year and outcome was assessed functionally by Oxford Shoulder Score (OSS) and radiologically. The patient had an excellent functional outcome with OSS of 48/48 and full range of motion without instability of AC-joint and good union radiologically. We report good outcome of segmental clavicle fracture with AC-joint disruption treated surgically and discuss relevant literature.
\end{abstract}

Keywords: Segmental clavicle fracture; acromioclavicular joint; K-wire; disruption

\begin{abstract}
*Corresponding author: Dr. Banda Naveen Kumar, Department of Orthopaedics, Krishna Institute of Medical Sciences, Minister Road, Secunderabad-500003, Telangana, India. Email: drnaveen1668@gmail.com
\end{abstract}

Received 22 October 2019; Revised 10 December 2019; Accepted 18 December 2019; Published 27 December 2019

Citation: Rao AS, Raju LVSN, Banda NK. Segmental clavicle fracture with acromioclavicular joint disruption: Report of a rare case. J Med Sci Res. 2020; 8(1):25-28. DOI: http://dx.doi.org/10.17727/ JMSR.2020/8-4

Copyright: (C) 2020 Rao AS et al. Published by KIMS Foundation and Research Center. This is an open-access article distributed under the terms of the Creative Commons Attribution License, which permits unrestricted use, distribution, and reproduction in any medium, provided the original author and source are credited.

\section{Introduction}

Clavicle fractures are common which accounts for $2.6 \%$ of all fractures in adults and $10 \%$ to $15 \%$ in children [1]. They are commonest in young males often resulting from sports injury or road traffic accidents. The most common mechanism of injury is a direct force to the clavicle or a fall onto the outstretched arm [2,3]. Mid-shaft clavicular fractures are the most common, ranging from $69 \%$ and $82 \%$, distal fractures comprise $21 \%$ to $28 \%$, and proximal fractures occur between $2 \%$ and $3 \%$ [4]. We could not find case of segmental clavicle fracture with acromioclavicular joint (AC-joint) disruption in English-literature. It was treated with lateral clavicular plate fixing both fractures and $\mathrm{K}$-wire for AC-joint disruption. Rare case reports have been published of AC-joint dislocations with ipsilateral mid-shaft clavicle fractures, including a 
series of four cases with a range of management and good outcomes [5-8]. We found one case report of a segmental clavicle fracture with sternoclavicular joint disruption [9].We were unable to find any cases reported in the literature with the fracture pattern in this case.

\section{Case report}

A 35-year-old patient presented to emergency department with pain in right shoulder following fall from motorcycle. On examination swelling was present over right clavicle area with tenderness over middle and lateral $1 / 3^{\text {rd }}$ clavicle including $\mathrm{AC}$-joint. Bony discontinuity was present with palpable ACjoint deformity. There was no open wound and no distal neuro vascular deficits. Radiograph (Figure 1) showed unusual presentation of segmental clavicle fracture which includes middle $1 / 3^{\text {rd }}$ and lateral end clavicle fracture with $\mathrm{AC}$-joint disruption. As it is obvious AC-joint dislocation on radiograph we didn't took opposite shoulder radiograph or same shoulder MRI. He was operated the next day after injury under general anesthesia. Open reduction and internal fixation was done with lateral clavicular plate fixing both fractures and K-wire for AC-joint disruption (Figure 2). AC-joint was stable with single $\mathrm{k}$-wire fixation. K-wire was left outside the skin and was removed after 3 weeks.

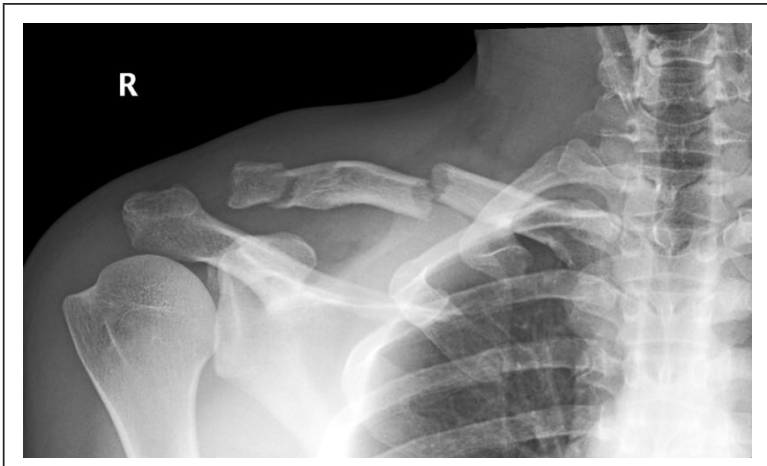

Figure 1: Radiograph showing segmental clavicle fracture with AC-joint dislocation.

Physical therapy for shoulder movement with active exercises was started. Bony union was achieved by 12 weeks (Figure 3) and the patient had pain-free full range of movements of shoulder joint (Figure 4). At 12 months after his initial surgery, the patient had an excellent outcome with an Oxford Shoulder Score of 48/48 and with a full clinical range of movement without instability of the $\mathrm{AC}$-joint. $\mathrm{He}$ has no restrictions in his work or hobbies, even returning to motorcycle riding.

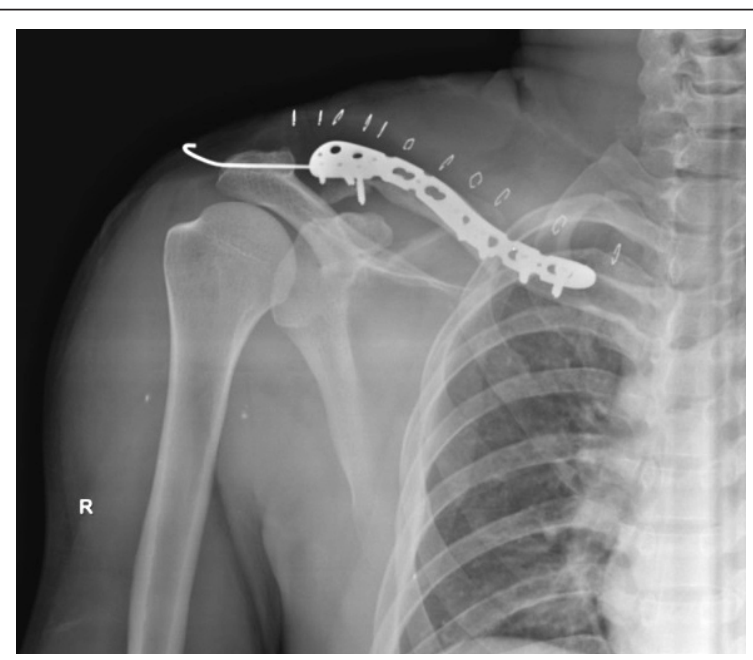

Figure 2: Immediate post-operative radiograph showing fracture fixed with plate and $\mathrm{K}$-wire fixation for $\mathrm{AC}$-joint.

\section{Discussion}

Segmental fractures of clavicle are rare. The segmental clavicle fracture is an uncommon pattern, with one study showing $0.8 \%$ of clavicle fractures to be segmental [10]. Although the majority of clavicle fractures are managed non-operatively, specific indications exist for operative intervention [11]. Segmental long bone fractures are considered unstable injuries with the risk of nonunion and nonoperative approach being considered unacceptable [12]. The clavicle forms an important structure which connects upper limb to the axial skeleton and it is important for the normal functioning of the upper limb. Non-union of the clavicle fracture would result in considerable functional disability. With little literature regarding segmental clavicle injuries, no consensus exists about the management of these fractures with some case reports advocating a nonoperative $[9,13]$ while others an operative approach $[12,14]$.

Osman et al. [15] treated a similar case of fracture of the diaphysis and lateral third of the clavicle, which was associated with ipsilateral rib fractures and consequent pneumothorax. The patient underwent plate osteosynthesis with subsequent removal of the plates since one of the screws caused an impact in the coracoid process, and also due to the risk of fracture between the plates. There are no rib fractures in our case. 


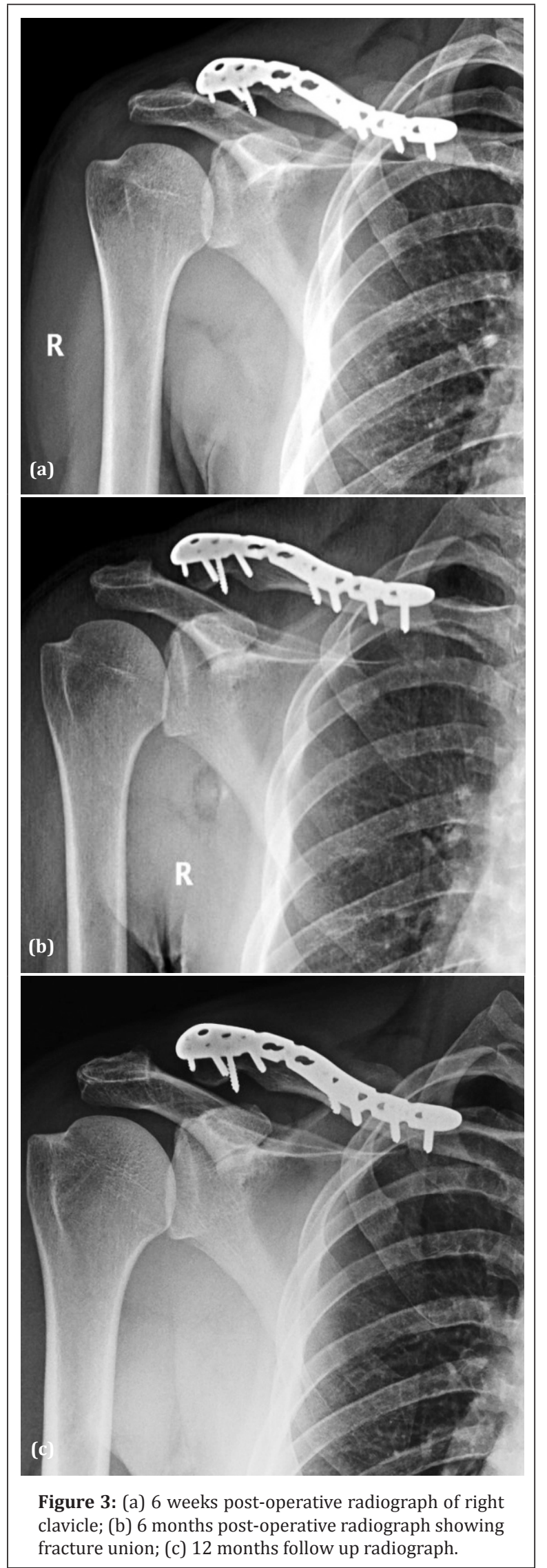

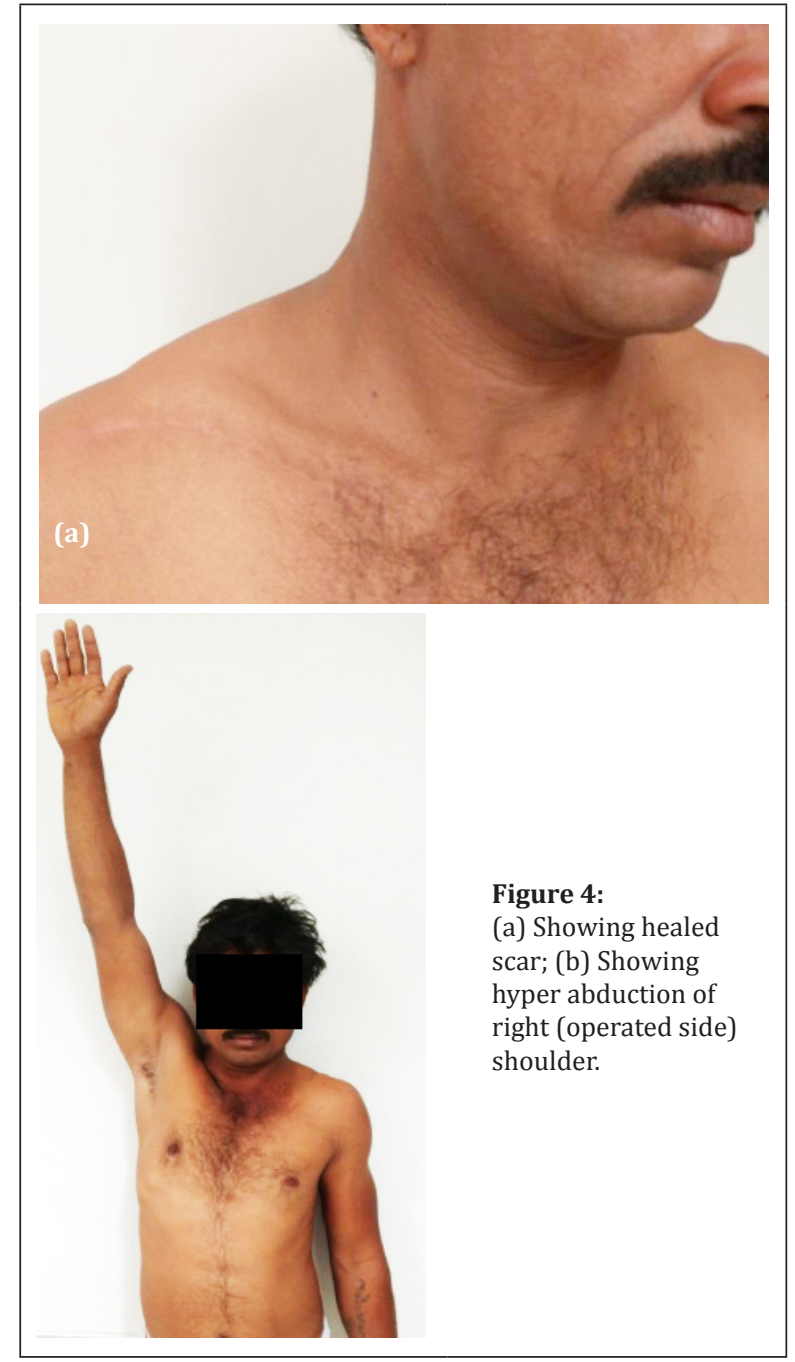

Miller et al. [16] presented a report of fracture of the medial and lateral extremity of the clavicle with the use of a reconstruction plate and another with locking T-plate. Our case had middle and lateral clavicle fracture treated with single plate. Karimi et al. [17] had a segmental clavicle fracture with rib fracture treated with plating. There is no rib fracture in our case.

\section{Conclusion}

Whenever patients present with clavicle fracture, he/she had to screen for segmental fracture. Often this type of fractures may be missed. So detailed clinical and radiological examination has to be done. Segmental fractures have to be operated to reduce the risk of non-union, pseudo-arthrosis.

\section{Conflicts of interest}

Authors declare no conflicts of interest. 


\section{References}

[1] Postacchini F, Gumina S, De Santis P, Albo F. Epidemiology of clavicle fractures. J Shoulder Elbow Surg. 2002; 11(5):452456.

[2] Robinson CM. Fractures of the clavicle in the adult. J Bone Joint Surg Br. 1998; 80(3):476-484.

[3] Stanley D, Trowbridge EA, Norris SH. The mechanism of clavicular fracture. A clinical and biomechanical analysis. J Bone Joint Surg Br. 1988; 70(3):461-464.

[4] Nordqvist A, Petersson C. The incidence of fractures of the clavicle. Clin Orthop Relat Res. 1994; (300):127-132.

[5] Daolagupu AK, Gogoi PJ, Mudiganty S. A rare case of segmental clavicle fracture in an adolescent. Case Rep Orthop. 2013; 2013:248159.

[6] Psarakis SA, Savvidou OD, Voyaki SM, Beltsios M, Kouvaras JN. A rare injury of ipsilateral mid-third clavicle fracture with acromioclavicular joint dislocation. Hand (NY). 2011; 6(2):228-232.

[7] Celenza M, Bertini G, De Tullio V, Guagnini M, Sarda G. A case of a fracture of the clavicle associated with an acromioclavicular luxation. Minerva Med. 1990; 81 (Suppl. 7-8):127-129.

[8] Wurtz LD, Lyons FA, Rockwood CA. Fracture of the middle third of the clavicle and dislocation of the acromioclavicular joint. A report of four cases. J Bone Joint Surg Am. 1992; 74(1):133-137.

[9] Pang KP, Yung SW, Lee TS, Pang CE. Bipolar clavicular injury. Med J Malaysia 2003; 58(4):621-624.

[10] Throckmorton T, Kuhn JE. Fractures of the medial end of the clavicle. J Should Elbow Surg. 2007; 16(1):49-54.

[11] Jupiter JB, Leffert RD. Non-union of the clavicle. Associated complications and surgical management. Journal of Bone and Joint Surgery. 1987; 69(5):753-760.

[12] Heywood R, Clasper J. An unusual case of segmental clavicle fracture. Journal of the Royal Army Medical Corps. 2005; 151(2):93-94.

[13] Sethi K, Newman SD, Bhattacharya R. An unusual case of bipolar segmental clavicle fracture. Orthop Rev. 2012; 4(3):e26.

[14] Miller D, Smith KD, McClelland D. Bipolar segmental clavicle fracture. European Journal of Orthopaedic Surgery and Traumatology. 2009; 19(5):337-339.

[15] Osman N, Sinopidis C, Gibson L. Unusual segmental fracture of clavicle associated with rib fractures and pneumothorax. J Orthop Surg. 2010; 15(2):1-5.

[16] Miller D, Smith K, Mc Clelland D. Bipolar segmental clavicle fracture. Eur J Orthop Traumatol. 2009; 19(5):337-339.

[17] Karimi A, Ettehad H, Akbar MH. Segmental fracture of the clavicle (a very rare case in trauma surgery) Shiraz E-Medical J. 2007; 8(2):90-95. 